\title{
A Study of Metallurgical Factors for Defect Formation in Electric Resistance Welded API Steel Pipes
}

\author{
MIN SUNG JOO, KYUNG-MIN NOH, WAN-KEUN KIM, JIN-HO BAE, \\ and CHANG-SUN LEE
}

A critical assessment has been made for the electric resistance welded API-J55 and P110 steel pipes to clarify the metallurgical factors crucial to the occurrence of welding defects. Electric resistance welding (ERW) is widely accepted due to its low cost and high efficiency of production as a conventional manufacturing technology for the steel pipes. However, ERW pipes are vulnerable to the defect formation because its welding zone has different characteristics compared to the base material. It has been found that there were two major crack types in the investigated steels: surface crack and hook crack (J-shaped crack). Macroscopic examinations suggested that the causes and occurrences of the cracks were distinct among the investigated steels. The small surface cracks were largely occurred in the API-J55 steel pipes. The microstructure in the vicinity of crack was identical to the matrix, but it was found that the formation of the surface cracks was attributed to the sulfur and oxide inclusions. The energy dispersive X-ray spectroscopy (EDS) analysis showed that the cracks were associated with hydrogen and clusters of complex oxide inclusions with calcium such as $\mathrm{Al}-\mathrm{Ca}-\mathrm{O}$ and $\mathrm{Fe}-\mathrm{Ca}-\mathrm{O}$. Moreover, sulfur was found to be the major culprit for the surface crack formation in the statistical evaluation. On the other hand, most of the hook cracks were large in size and occurred in the API-P110 steel pipes even though the sulfur level was very low, where the phosphorous was critical to the occurrence of hook crack. Although the EDS analysis showed the similar oxides compared to the case of surface cracks, B and P segregation were found in secondary ion mass spectrometry and electron probe micro analyzer analyses. In the vicinity of the hook cracks, martensite (locally hardened microstructure) was formed because the segregation enhances the hardenability. Eventually, the crack propagates along the martensite which was the band of ferrite and pearlite. It is postulated that the hook crack in API-P110 steel pipes is initiated from the oxides with hydrogen and propagated along the banded microstructure with the prior austenite grain boundaries where culprit elements can be segregated.

DOI: $10.1007 / \mathrm{s} 40553-015-0049-6$

(C) ASM International (ASM) and The Minerals, Metals \& Materials Society (TMS) 2015

\section{INTRODUCTION}

ERW is widely accepted due to its low cost and high efficiency of production as a conventional manufacturing technology for the steel pipes. In particular, ERW steel pipes with high performance and low cost for Oil Country Tubular Goods (OCTG) are strongly demanding due to an increase in mining depth and a pullback in natural gas prices. ${ }^{[1,2]}$ However, ERW steel pipes are vulnerable to the defect formation because its welding zone has different characteristics compared to the base material. This limits the application possibility of ERW steel pipes and has become a major concern. ${ }^{[3-7]}$ In this study, a critical assessment

MIN SUNG JOO, KYUNG-MIN NOH, and WAN-KEUN KIM, Senior Researchers, JIN-HO BAE, Senior Principal Researcher, and CHANG-SUN LEE, Director, are with the POSCO Computational Optimization of API Steels (PosCOA) Research Project Team, Technical Research Laboratories, POSCO, Pohang, Republic of Korea. Contact e-mails: athpimo@postech.ac.kr,msjoo@posco.com Manuscript submitted November 16, 2014.

Article published online May 12, 2015 has been made for the electric resistance welded American Petroleum Institute (API) J55 and P110 steel pipes to clarify the metallurgical factors crucial to the occurrence of welding defects. Various J55 and P110 steel pipes with different sulfur and phosphorous contents were investigated to explore the effect of sulfur and phosphorous on the defect formation. The experimental analysis for oxide inclusions, finite element analysis for effective stress, and statistical evaluation for defect occurrences have been conducted in order to reveal detailed information on the mechanism of crack formation and propagation.

\section{EXPERIMENTAL TECHNIQUE}

The chemical compositions and processing variables of the steel sheets are listed in Table I. The slabs were subjected to austenitization $\left[T>1373 \mathrm{~K}\left(1100{ }^{\circ} \mathrm{C}\right)\right]$ and hot-rolled above the $\mathrm{Ar}_{3}$, the temperature at which austenite begins to transform into ferrite during cooling. Then the steel sheets were manufactured as ERW steel 
pipes. Detailed descriptions for ERW process can be found elsewhere. ${ }^{[8-10]}$ Processing conditions of ERW were maintained the same during pipes manufacturing. After the ERW process, P110 steel pipes underwent additional heat treatments, for example, full body normalizing (austenitizing), quenching, and tempering processes to achieve the required mechanical properties as shown in Figure 1(b), where API-J55 does not need the heat treatment. Please note that tempering temperature and time can be varied according to thickness of pipes and limitation of facilities. The defects in the pipes were revealed using ordinary ultrasonic inspection after the ERW process and before the additional heat treatment since the heat treatment cannot fix the defects already established in the ERW process. ${ }^{[1]}$ All the chemical composition and processing conditions meet the API-5CT specification. ${ }^{[12]}$ The final thicknesses of the steel sheets and outside diameters (OD) of steel pipes were diversified to elucidate the relationship between thickness over OD of pipe (T/D) and defect arrestability (final thickness: $<12 \mathrm{~mm}$, OD: 4 to 16 in.) since T/D can be used as the index to represent the amount of plastic deformation given in the pipes. Also, the effect of phosphorous and sulfur on the defect arrestability in welding has been assessed by statistical evaluation.

Finite element analyses (FEA) using ABAQUS commercial software ${ }^{[13]}$ were carried out in order to investigate the effect of T/D and effective stress on the crack arrestability. The properties of the materials for the analyses are listed in Table II. Note that T/D for LTD55 was actually 4.82 , but 4.92 pct was used in the simulation to compare with LTD110. Ludwik's equation $\sigma=\sigma_{0}+K \varepsilon^{n}$ with $n=0.3$ was used to apply the work hardening effect during analyses, where $\sigma$ is the stress, $\sigma_{0}$ is the yield stress, $K$ is the strength coefficient, $\varepsilon$ is the strain, and $n$ is the strain hardening exponent. Figure 2 shows the pipe forming during the simulation. Additional conditions for the numerical analyses can be found in Reference 14. Furthermore, residual stress in a steel pipe was measured using instrumented indentation technique. ${ }^{[15]}$ The reference sample was collected from the steel sheet to evaluate the relative residual stress in the steel pipe.

Microstructural studies were carried out using optical and scanning electron microscopy (SEM). The samples were prepared by polishing and etching using 2 pct nital. Samples were mechanically polished with colloidal silica in the final polishing stage for inclusion detection and chemical composition/segregation analyses in the vicinity of defects using energy dispersive X-ray spectroscopy (EDS), secondary ion mass spectrometry (SIMS), and electron probe micro analyzer (EPMA). The fraction of microstructural constituents was evaluated using an image analysis software.

Thermal desorption spectroscopy (TDS) with gas chromatography was conducted at constant heating rates of $100 \mathrm{~K} \mathrm{~h}^{-1}\left(100{ }^{\circ} \mathrm{C} \mathrm{h}^{-1}\right)$ to a maximum temperature of $573 \mathrm{~K}\left(300{ }^{\circ} \mathrm{C}\right)$. The samples for TDS were cut from base material and welding zone with/without defect formation in the J55 steel pipes and P110 steel

Table I. Chemical Compositions (Weight Percent) and Thermomechanical Processing Variables

\begin{tabular}{|c|c|c|c|c|c|c|c|c|c|c|}
\hline & $\mathrm{C}$ & $\mathrm{Mn}$ & $\mathrm{Si}$ & $\mathrm{Cr}+\mathrm{Mo}+\mathrm{V}$ & $\mathrm{Ni}+\mathrm{Cu}$ & $\mathrm{Nb}+\mathrm{Ti}+\mathrm{Al}$ & $\mathrm{N}$ & $\mathrm{B}$ & $\mathrm{P}$ & $\mathrm{S}$ \\
\hline API-J55 & $<0.3$ & $<2.0$ & 0.20 & $<0.03$ & $<0.03$ & $<0.05$ & $<0.008$ & - & 0 to 0.02 & 0 to 0.003 \\
\hline \multicolumn{4}{|c|}{$\begin{array}{l}\text { API-P110 } \\
\text { Reheating temperature }\end{array}$} & & & $<0.1$ & & $<0.003$ & & \\
\hline \multicolumn{4}{|c|}{ Reheating temperature } & \multicolumn{7}{|c|}{$1373 \mathrm{~K}$ to $1453 \mathrm{~K}\left(1100{ }^{\circ} \mathrm{C}\right.$ to $\left.1180{ }^{\circ} \mathrm{C}\right)$} \\
\hline \multicolumn{4}{|c|}{ Start cooling temperature } & \multicolumn{7}{|c|}{ above $\mathrm{Ar}_{3}$} \\
\hline \multicolumn{4}{|c|}{ Finish rolling temperature } & \multicolumn{7}{|c|}{ above $\mathrm{Ar}_{3}$} \\
\hline \multicolumn{4}{|c|}{ Coiling temperature } & \multicolumn{7}{|c|}{$>773 \mathrm{~K}\left(500^{\circ} \mathrm{C}\right)$} \\
\hline \multicolumn{4}{|c|}{ Final thickness } & \multicolumn{7}{|c|}{$<12 \mathrm{~mm}$} \\
\hline
\end{tabular}

$\mathrm{Ar}_{3}$ represents the temperature at which austenite begins to decompose during cooling. Please note that the exact chemical compositions and processing variables are proprietary information.

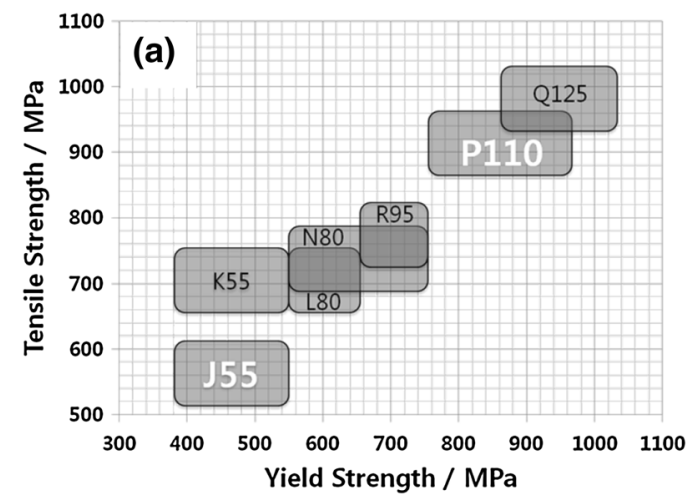

(b)

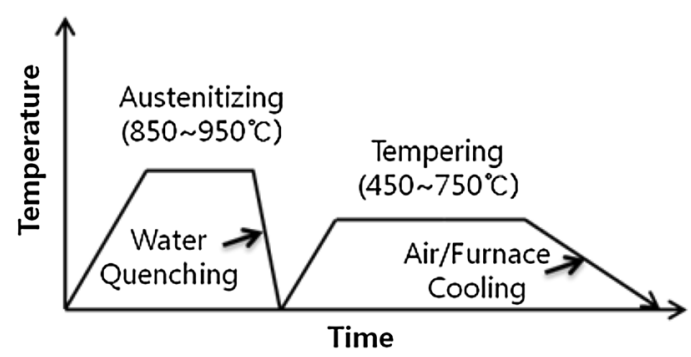

Fig. 1-(a) Requirements of mechanical properties in API-5CT specification. ${ }^{[15]}$ Please note that there are no maximum limitations of tensile strength in the specification but here we add the maximum lines for the clarity, and $(b)$ A schematic diagram of the additional heat treatment for API-P110. The duration times for austenitizing and tempering can be diversified according to the target temperatures. 
Table II. Mechanical Properties of the Investigated Steel Pipes

\begin{tabular}{lccccccc}
\hline & Designation & $\begin{array}{c}\text { Yield Strength } \\
(\mathrm{MPa})\end{array}$ & $\begin{array}{c}\text { Tensile Strength } \\
(\mathrm{MPa})\end{array}$ & $\begin{array}{c}\text { Elongation } \\
(\mathrm{pct})\end{array}$ & $\begin{array}{c}\text { Thickness } \\
(\mathrm{mm})\end{array}$ & $\begin{array}{c}\text { OD } \\
(\mathrm{mm})\end{array}$ & $t / D(\mathrm{pct})$ \\
\hline J55 & HTD55 & 500 & 660 & 27.5 & 5.51 & 73 & 7.6 \\
& LTD55 & & & & 6.74 & 139.7 & 4.92 \\
P110 & HTD110 & 450 & 660 & 30 & 10.54 & 139.7 & 7.6 \\
& LTD110 & & & & 9.53 & 193.7 & 4.92 \\
\hline
\end{tabular}
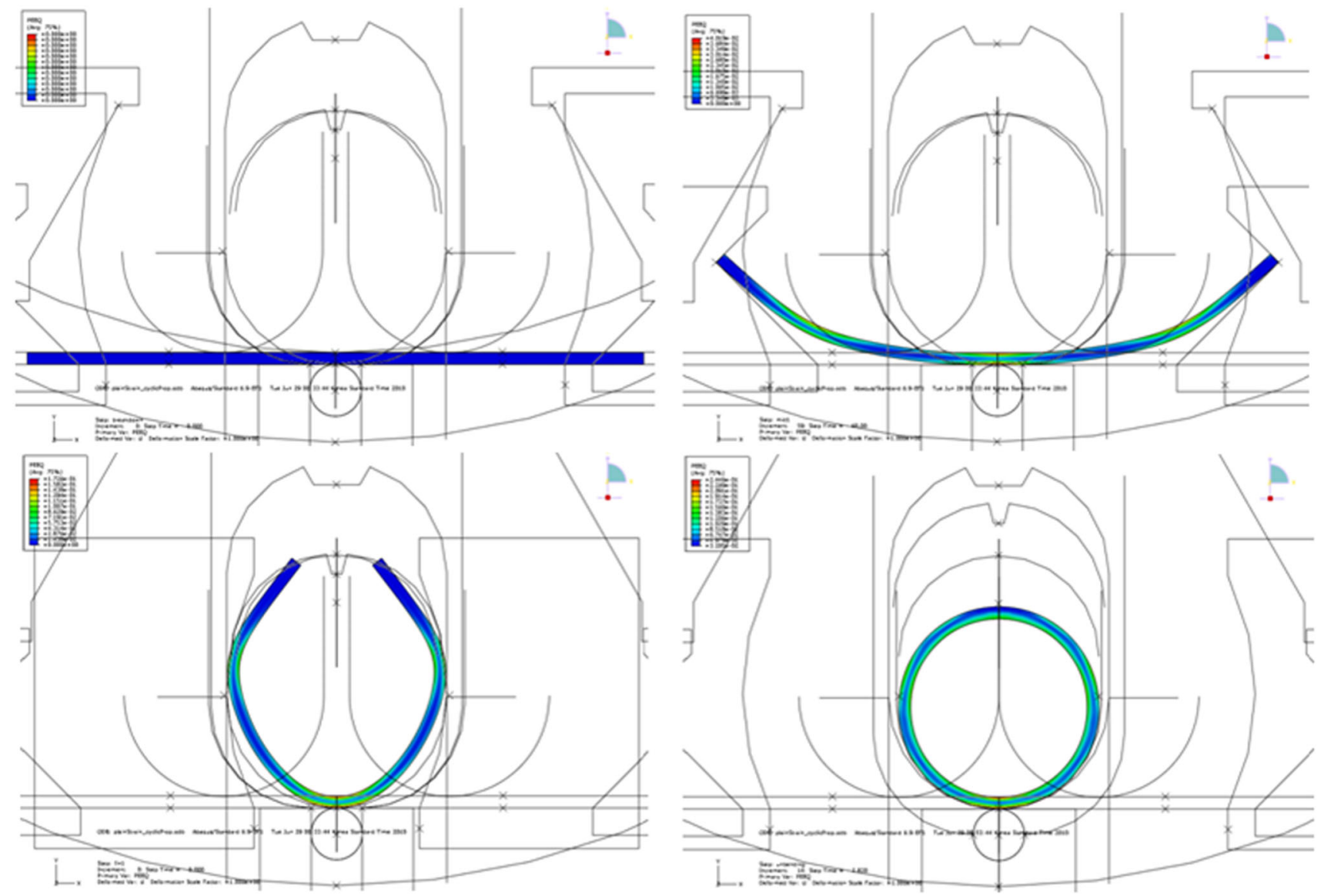

Fig. 2-Pipe forming during simulation.

pipes before the additional heat treatment. Because of the additional heat treatment can diffuse out all the hydrogen in the specimen, it is not necessary to measure the hydrogen contents for the P110 steel pipes after the heat treatment. Since the experiment should be conducted immediately after the pipe forming process in order to avoid dissipation of diffusible hydrogen contents, a single measurement was taken due to the limitation of specimen preparations for each case (base and welding zone with/without crack in J55 and P110). The size of specimen was $75 \mathrm{~mm} \times 12 \mathrm{~mm} \times$ thickness. The sample gas was analyzed at 5 minutes intervals using helium as a carrier gas when a standard mixture $\mathrm{He}+10.2$ volume ppm of $\mathrm{H}_{2}$ was used for the calibration. Desorption rate was defined as the amount of hydrogen evolved in 1 minute per gram of the specimen.
Mechanical properties were evaluated by tensile, Charpy, and hardness tests. Multiple measurements were performed for obtaining the mechanical properties ( 3 times for tensile test, 3 times for Charpy test, and more than 10 times for hardness test). Tensile specimens were machined according to the flat-test specimen ASTM E8 standard with gage length of $50.8 \mathrm{~mm}$. The experiments were conducted at room temperature, using crosshead speed of $3.6 \mathrm{~mm} \mathrm{~min}^{-1}$ (strain rate approximation $0.001 \mathrm{~s}^{-1}$ ). Tensile tests were conducted that Charpy specimens were machined according to the ASTM A370 standard, Charpy V-notched specimens. The sizes of Charpy specimens were varied according to the thicknesses of steel sheets/pipes, and the observed energy of sub-sized specimen was converted into the energy for full-sized specimen according to the absorbed energy reduction factor of API-5CT specification (1.0 
for full-sized, 0.80 for $3 / 4$ sub-sized, 0.55 for $1 / 2$ subsized). ${ }^{[12]}$ Hardness tests were carried out with various loads and dwell times in order to ensure accurate hardness value. Eventually, macroscopic tests were conducted with a load of $0.5 \mathrm{kgf}$ and dwell time of 10 seconds. Microscopic tests were also conducted with a load of $50 \mathrm{gf}$ and dwell time of 10 seconds to discriminate microstructural constituents such as ferrite, pearlite, and martensite in the investigated steels.

\section{RESULTS AND DISCUSSION}

\section{A. Microstructure and Mechanical Properties}

The microstructure of API-J55 steel sheets with different phosphorous and sulfide contents in Table I is typical ferritic-pearlitic as shown in Figure 3(a). The fractions of the ferrite and pearlite are approximately 1:1. After the ERW process, the microstructure of the base material had not been changed, but the welding line showed allotriomorphic ferrite mostly (white area) ${ }^{[16]}$ due to the decarburization ${ }^{[17]}$ during welding as shown in Figures 3(b) and (c). Allotriomorphic ferrite is sometimes referred to as 'proeutectoid ferrite' (also grain boundary ferrite or polygonal ferrite), but the latter is a more general term, and its diffusional mechanism of formation remains it with a relatively small dislocation density, and as a result, each grain of such ferrite is free from large distortions and has a uniform crystallographic orientation. ${ }^{[19]}$ API-
P110 showed the same microstructure with API-J55 before and after the ERW process as shown in Figures 4(a) and (b), but it was changed to tempered martensite according to the additional heat treatment as shown in Figures 4(c) and (d). Mechanical properties of J55 and P110 steel pipes in Table III meet the requirement of API specification as shown in Figure 1(a).

\section{B. Defects}

The welding region of $\mathrm{J} 55$ and P110 steel pipes was investigated using ultrasonic inspection ${ }^{[1,12]}$ after the ERW process, and Figure 5 illustrates the percentage fractions of important defects types found. Most of the defects were revealed as hook crack and surface crack. It is interesting to note that the most of the hook crack were found in P110 steel pipes when the most of the surface cracks were majority in J55 steel pipes. Figure 6 shows the optical micrographs of cross sections of surface and hook cracks. The surface crack is relatively small, and the hook crack is very huge. Although there is a possibility that the crack was originated from the inadequate ERW process, such as scratch occurred in cutting of the welding flash resulting from the pressure during welding, ${ }^{[18]}$ we concentrate on the metallurgical factors here.

\section{The surface crack in J55}

The surface crack in J55 was formed relatively far from the welding line but in HAZ. The size of heat affected zone (HAZ) was approximately $2 \mathrm{~mm}$, and most of the cracks were found in the edge of HAZ. This
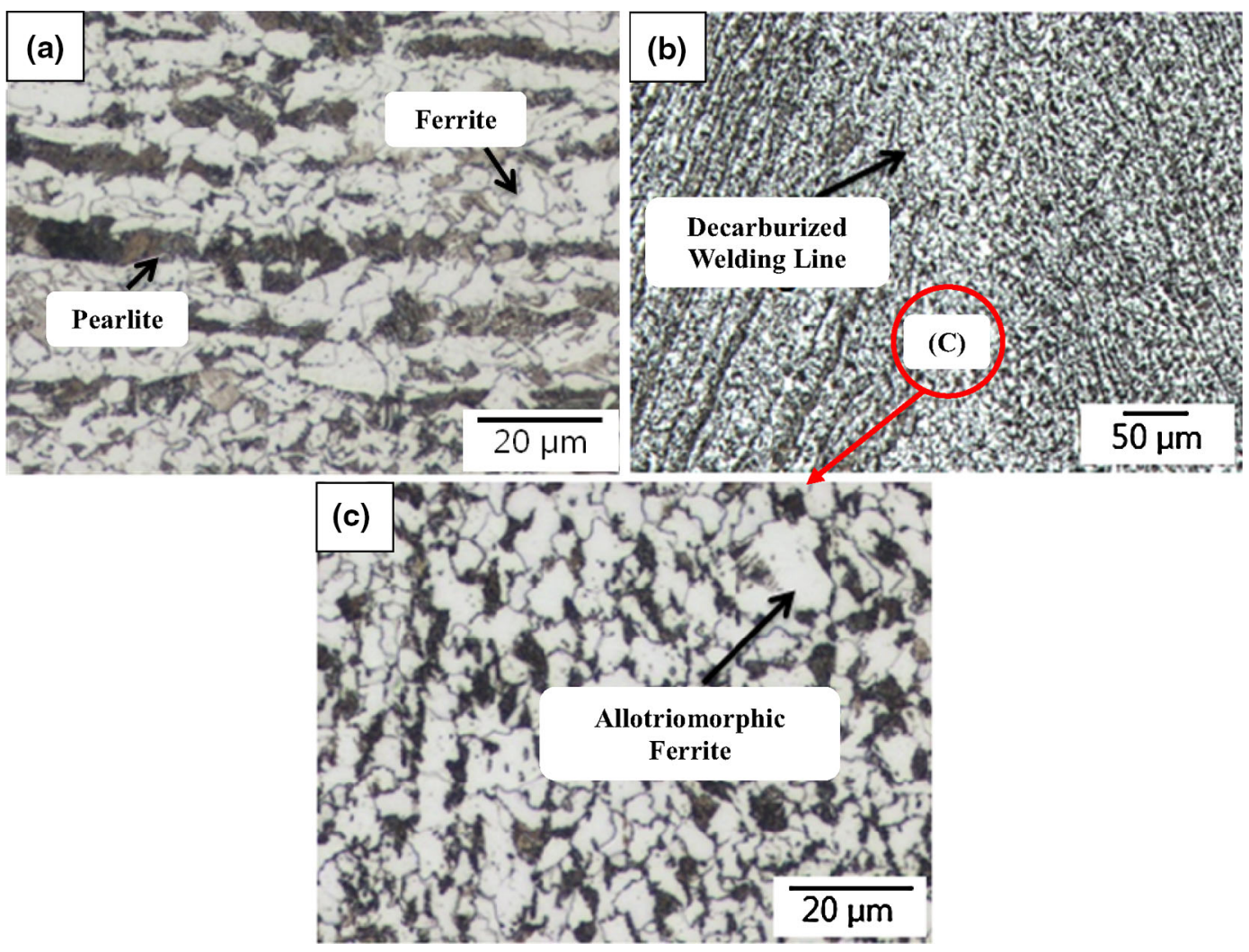

Fig. 3-Optical micrographs in API-J55: (a) microstructure of steel sheet before ERW process, $(b)$ decarburized welding line, and $(c)$ allotriomorphic ferrite in welding line after ERW process, indicated as (c) in the (b). 

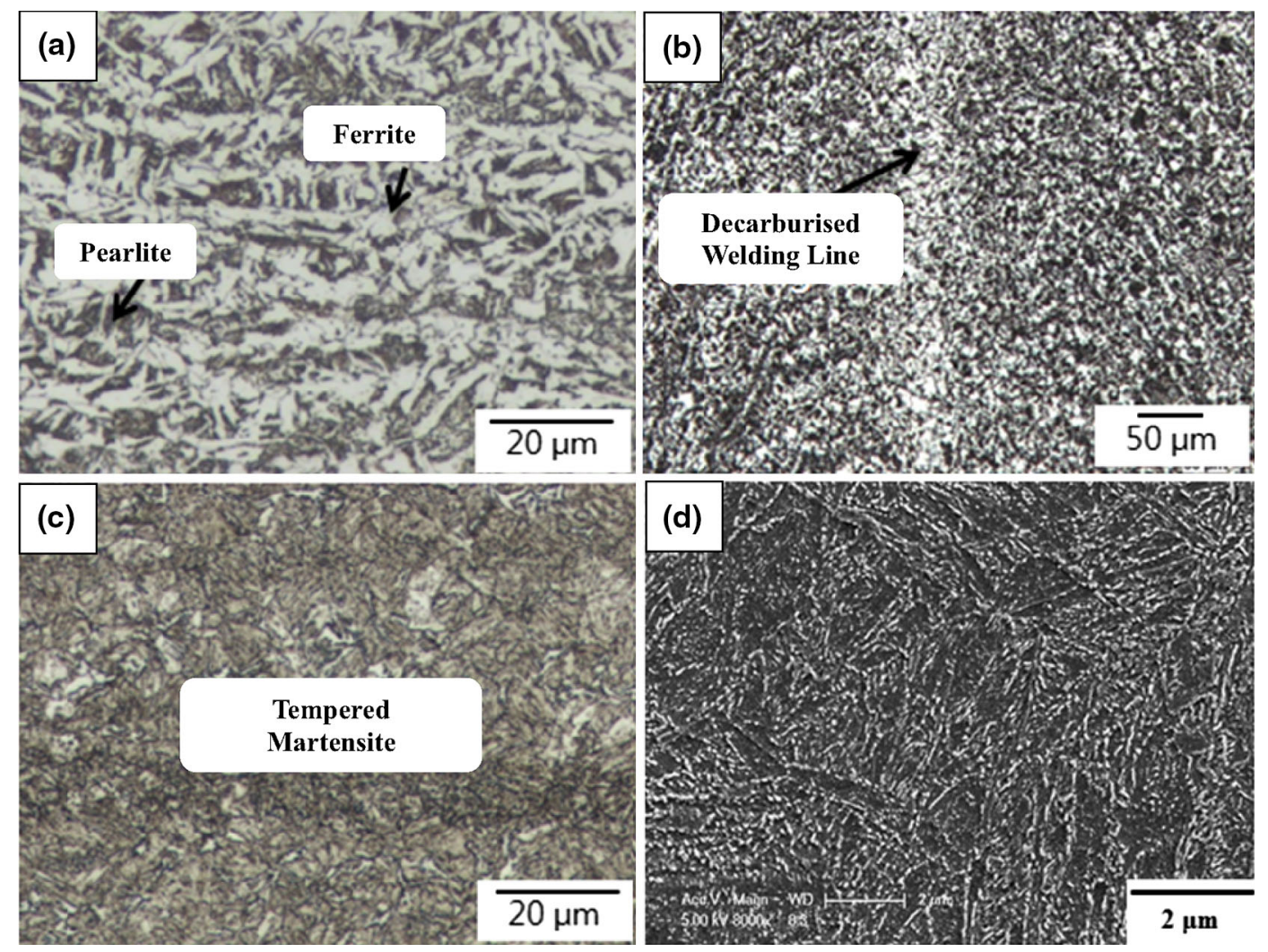

Fig. 4-Micrographs in API-P110: optical micrograph of $(a)$ steel sheet before ERW process and $(b)$ optical micrograph of decarburized zone after ERW process, $(c)$ optical micrograph, and $(d)$ scanning electron micrograph of steel pipe after the heat treatment.

Table III. Mechanical Properties of the Investigated Steel Pipes

\begin{tabular}{lccccccc}
\hline & $\begin{array}{c}\text { Yield Strength } \\
(\mathrm{MPa})\end{array}$ & $\begin{array}{c}\text { Tensile Strength } \\
(\mathrm{MPa})\end{array}$ & $\begin{array}{c}\text { Elongation } \\
(\mathrm{pct})\end{array}$ & $\begin{array}{c}\text { Charpy } \\
\text { Toughness }(\mathrm{J})\end{array}$ & $\begin{array}{c}\text { Hardness } \\
(\mathrm{HV})\end{array}$ & $\begin{array}{c}\text { Thickness } \\
(\mathrm{mm})\end{array}$ & OD (in.) \\
\hline J55 & & & & & & $<12$ & 4 to 16 \\
After ERW & $582 \pm 9$ & $680 \pm 5$ & $28.0 \pm 0.3$ & $144 \pm 7$ & $215 \pm 6$ & & \\
P110 & & $683 \pm 7$ & $27.6 \pm 0.3$ & $156 \pm 11$ & $220 \pm 6$ & & \\
After ERW & $582 \pm 8$ & $985 \pm 20$ & $19.2+1.4$ & $78 \pm 4$ & 294 & \\
After Q\&T & $880 \pm 27$ & & &
\end{tabular}

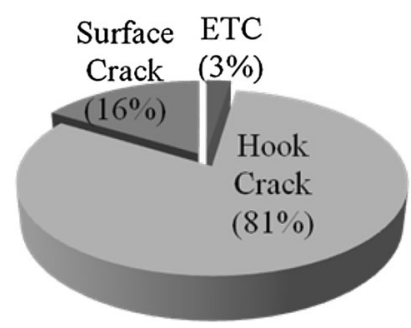

Fig. 5-Percentage fractions of defects types found in the investigated steel pipes.

implies that inhomogeneity between matrix and HAZ was the latent cause of the crack formation. However, the microstructure in the vicinity of the crack was identical to the matrix as shown in Figure 6(a), but it was found that the formation of the cracks was attributed to oxide inclusions. The EDS analysis showed that the cracks were associated with clusters of complex oxide inclusions with calcium such as $\mathrm{Al}-\mathrm{Ca}-\mathrm{O}$ and $\mathrm{Fe}-$ $\mathrm{Ca}-\mathrm{O}$ as shown in Figures 7(a) and (b). Generally, oxide inclusion is detrimental to the properties of material, ${ }^{[19]}$ since it serves to concentrate stress and nucleate voids. Furthermore, the material experienced bending strain up to 5 pct and longitudinal strain up to 3 pct coming from the pass line change for the sake of pipe forming during the ERW pipe forming. ${ }^{[20]}$ In particular, there should be tensile deformation in the outside surface area of the pipe. This is the reason why the crack is formed outside of the pipes normally. The formation of voids causes crack initiation in the vicinity of the oxide inclusions, and subsequently, the crack propagates toward the outer surface because of the tensile stress in the circumferential direction on the outside of pipes during pipe forming. In particular, cracks are mostly occurred in welding region due to the additional tensile residual stress imposed on welding region during welding process. 

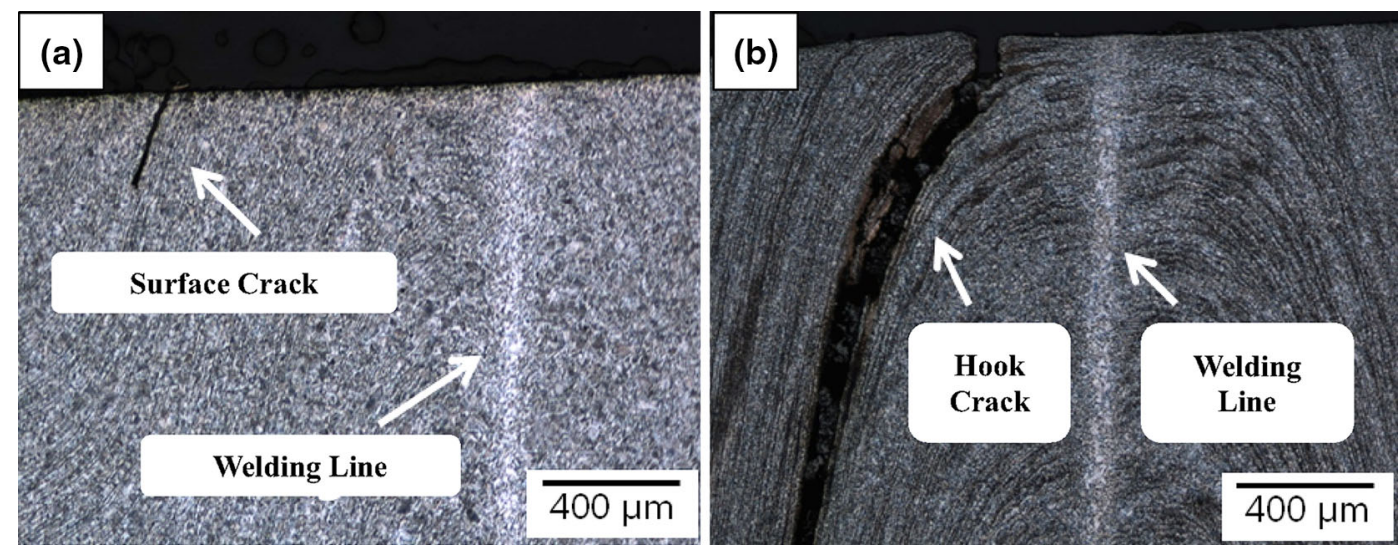

Fig. 6 - Optical micrographs of cross sections of $(a)$ surface and $(b)$ hook cracks. Note that the hook crack cannot be presented fully due to its enormous size.

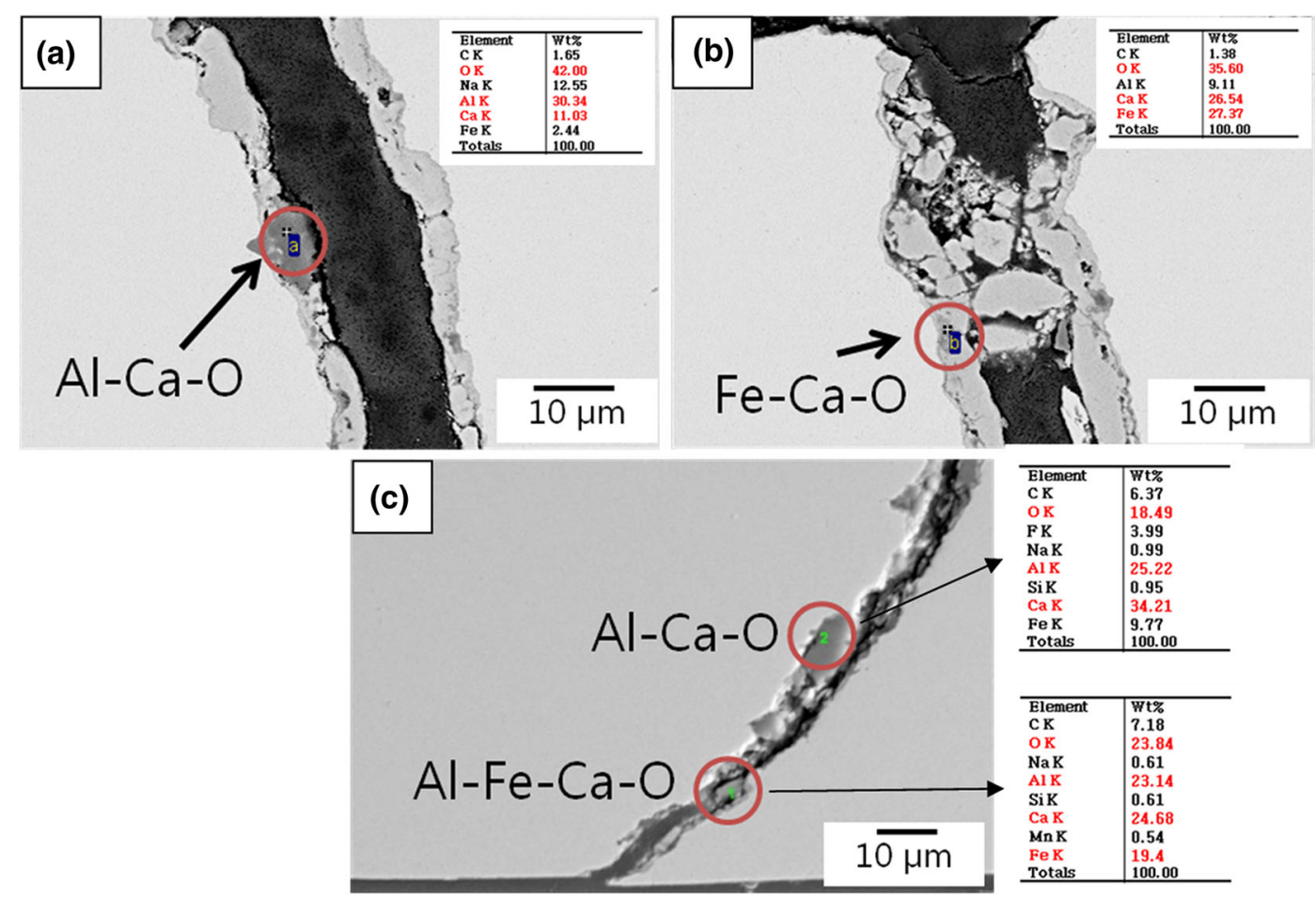

Fig. 7-Clusters of complex oxide inclusions with calcium, (a) Al-Ca-O, and (b) Fe-Ca-O in surface cracks of J55 and (c) oxides in hook crack of P110.

\section{The hook crack in P110}

The hook crack is known to be the most critical defect detected in the pipeline steel pipes. ${ }^{[21]}$ The hook crack in P110 was formed near to the welding line compared to the surface crack. The propagation path of the crack coincides with banded microstructure of the ferrite and pearlite, especially quarter of the thickness. Also, similar oxides were found in the crack as shown in Figures 7(c). The microstructure near the crack is totally different from base material as shown in Figures 6(b) and 8. Along the crack propagation, martensite is observed with higher hardness when the base material shows ferrite-pearlite microstructure with lower hardness as shown in Figure 8(b). This means that hardenability in the vicinity of the crack is higher than the base material.

Figure 9 shows the results of SIMS analyses. Segregation of $\mathrm{C}, \mathrm{B}$, and $\mathrm{Mn}$ was revealed in the crack propagation path. Furthermore, segregation of $\mathrm{P}$ and $\mathrm{S}$ was also observed from the EPMA analyses as shown in Figure 10. Segregation of $\mathrm{P}$ at grain boundaries could be a rejection from growing carbides. ${ }^{[22]}$ In addition, except $\mathrm{S}$, it is well known that other segregated elements can enhance the hardenability. ${ }^{[2,23]}$ However, segregation of $\mathrm{C}$ and $\mathrm{Mn}$ was found in the J55 steel pipes. Therefore, the segregation, especially for the boron, markedly retards the ferrite reaction ${ }^{[22]}$ and consequently im- 


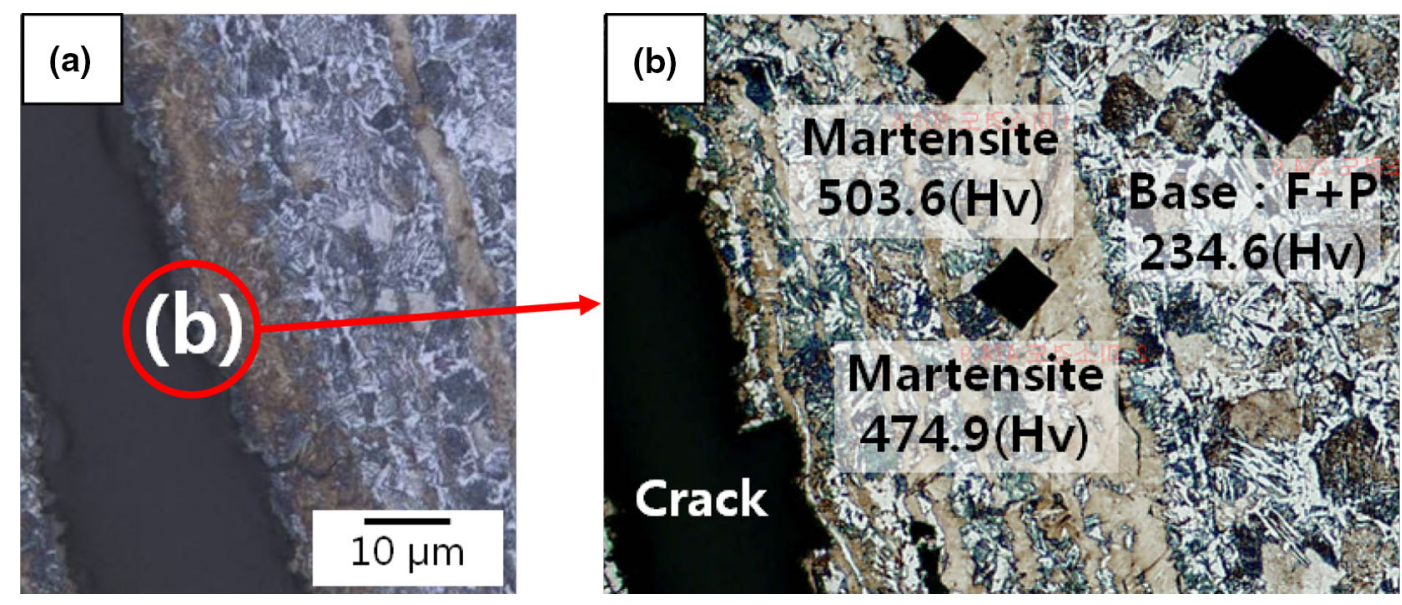

Fig. 8-Hardness in the vicinity of hook crack. Along the crack propagation, martensite is observed with higher hardness when the base material shows ferrite-pearlite microstructure with lower hardness. $\mathrm{F}+\mathrm{P}$ stands for ferrite + pearlite.
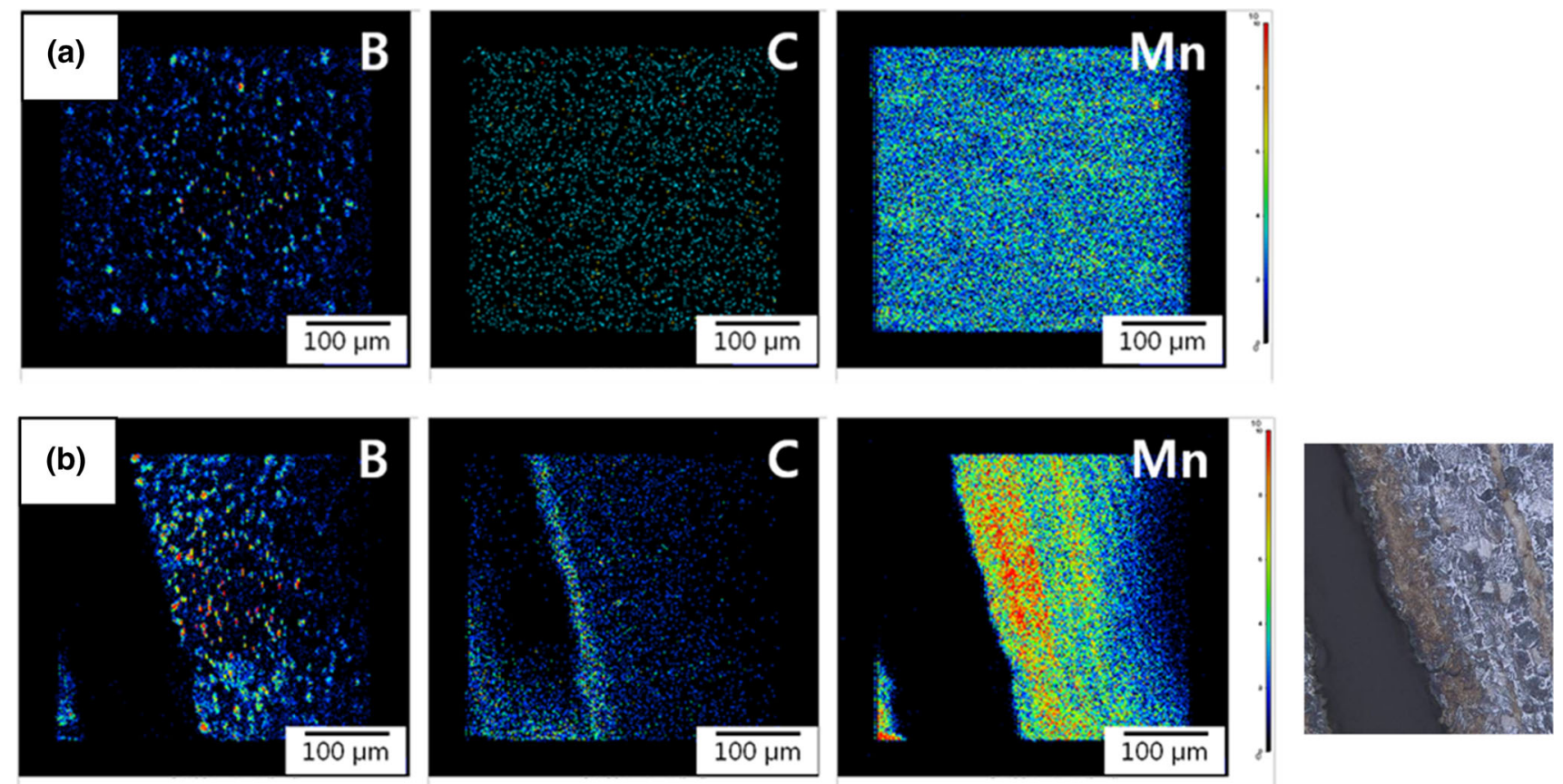

Fig. 9-SIMS results for $(a)$ base material and $(b)$ the hook crack. Segregation of B, C, and Mn is observed in the hook crack. Note that the hook crack is identical to Fig. 8(a).
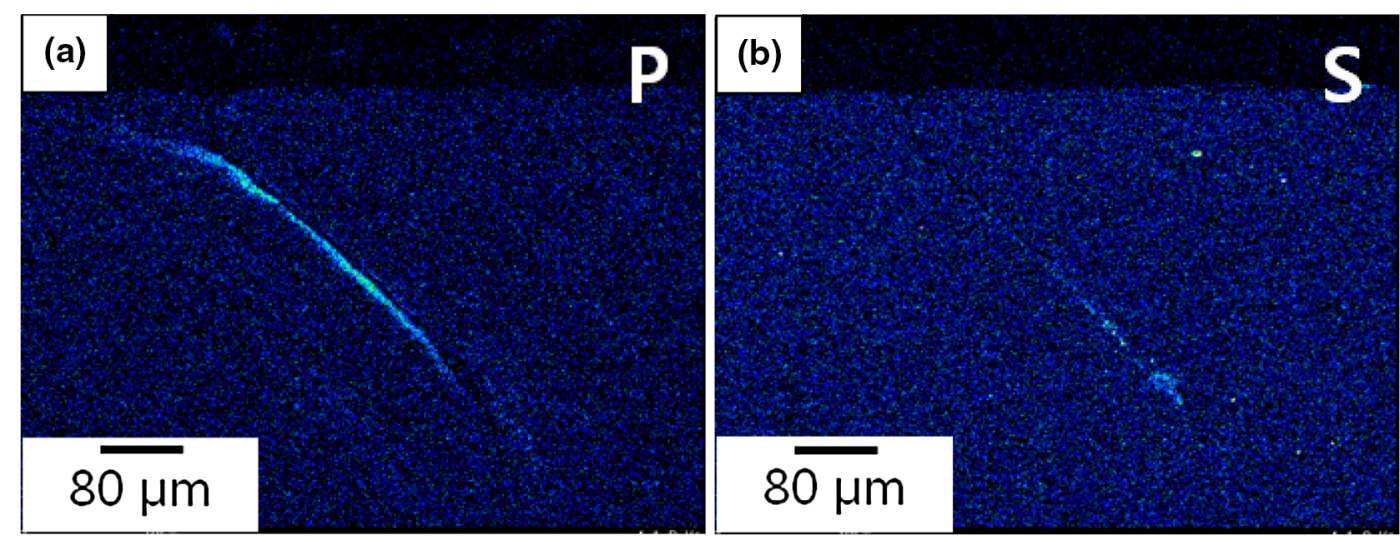

Fig. 10-EPMA results for hook crack, (a) phosphorus and (b) sulfur. 
proved the hardenability. Therefore, it leads the locally hardened microstructure which coincides with the banded microstructure. It is interesting to say that phosphorous and boron were both segregated in the vicinity of the crack although boron is known to suppress the segregation of phosphorous due to its own segregation

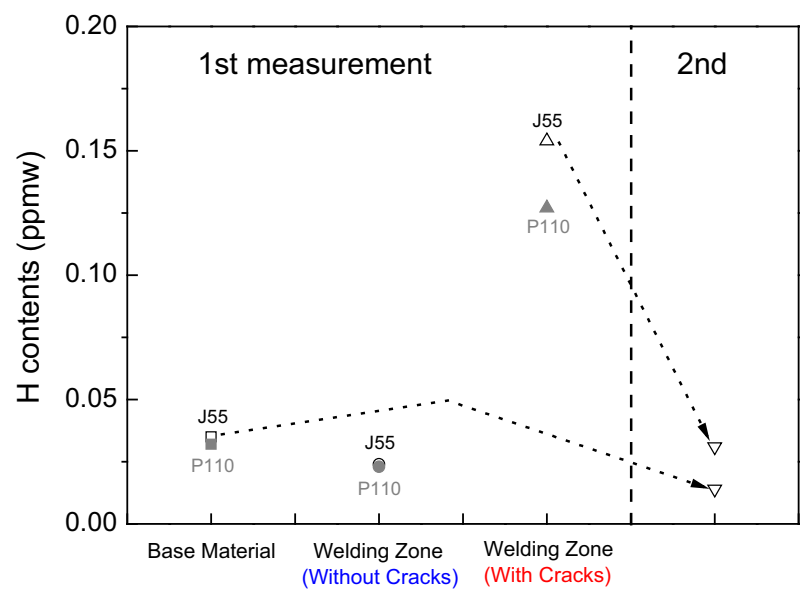

Fig. 11-Diffusible hydrogen contents of samples from API-J55/ P110 steel pipes.
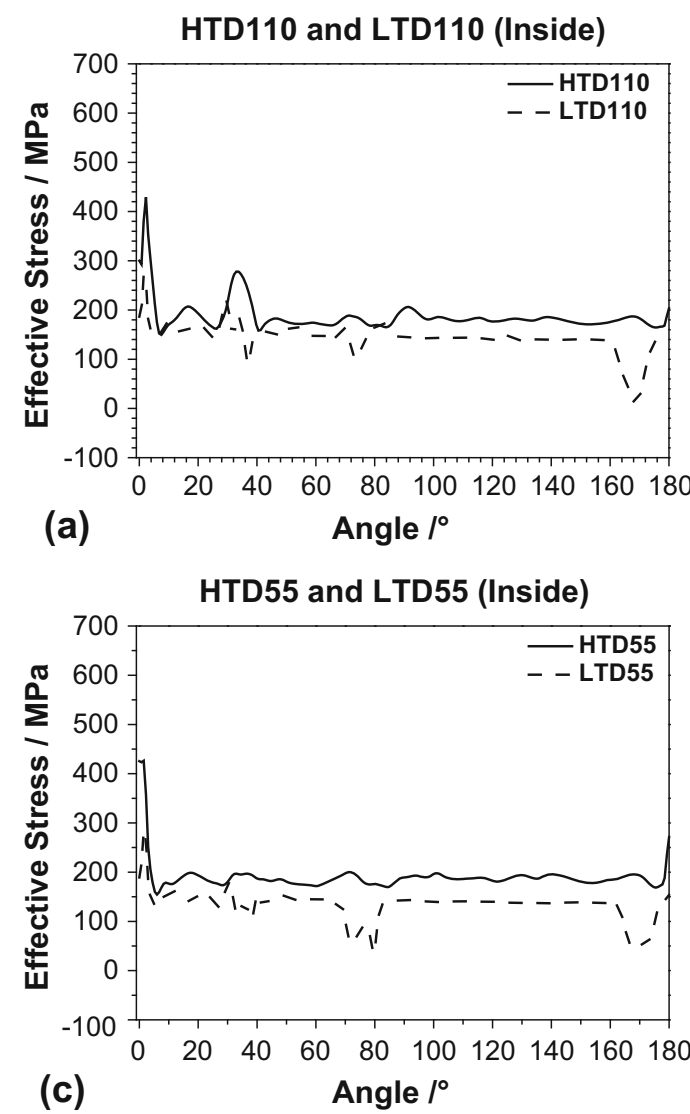

on the prior austenite grain boundaries. ${ }^{[24]}$ Presumably, boron segregated in the prior austenite grain boundaries first, and then phosphorous segregated in the boundaries and grains near the boundaries and stabilized the prior austenite grains, which resulted in the enhancement of hardenability. In common with the surface crack, the oxide inclusions led crack initiation and then the crack propagated along the hardened region with the prior austenite grain boundaries in welding region under tensile residual stress, which is vulnerable to the crack propagation. Finally, the crack became larger.

\section{Diffusible Hydrogen Content and Effective Stress in the Welding Region}

The oxide inclusions actually can be found in anywhere in the steel pipes. However, the cracks related to the inclusions were normally found in the welding zone in present study. Indeed, there are more points which should be considered, such as effective stress and hydrogen in the welding zone. It is widely accepted that the presence of hydrogen in steels is deleterious to properties. Even very small contents of hydrogen $\left(<2\right.$ ppmw) can be detrimental. ${ }^{[22,23,25]}$ Since the diffusivity of the hydrogen in ferritic (BCC) steels is high enough, hydrogen can be accommodated in the trap site easily $^{[26,27]}$ and result in rupture. Chapetti et al. reported
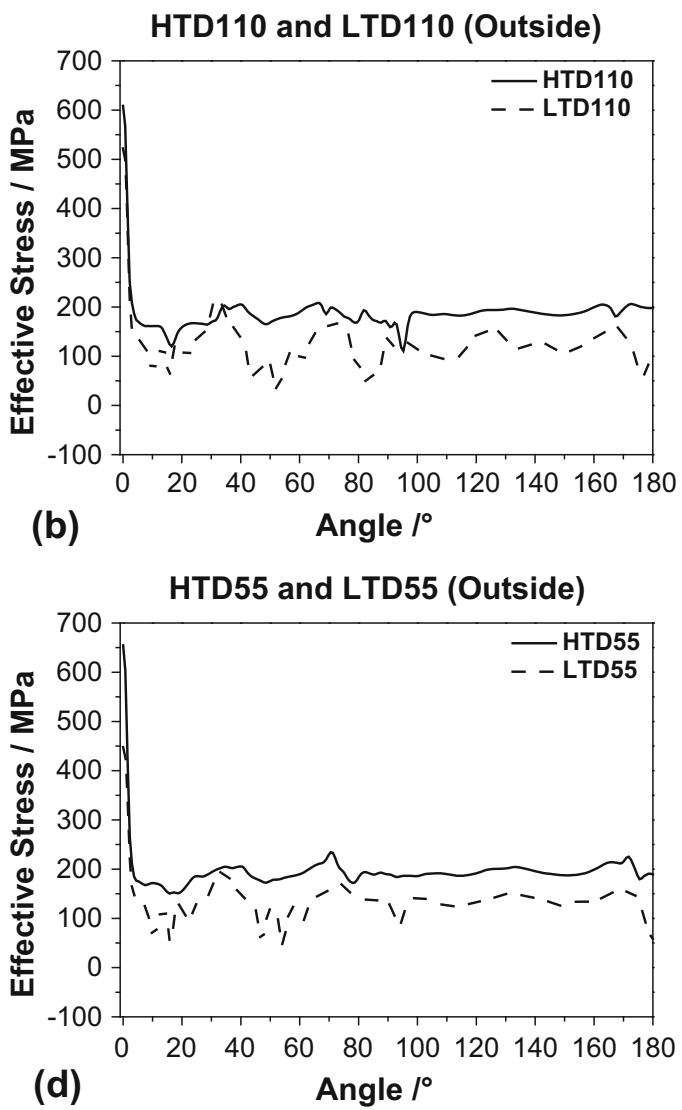

Fig. 12-FEA simulation for the pipe forming: comparison of effective stresses at $(a)$ inside and $(b)$ outside of P110 pipes with different T/D, $(c)$ inside and $(d)$ outside of J55 pipes with different T/D. Angle means the angular distance from the welding zone $(0$ deg) in the circumferential direction. 
HTD110 and HTD55 (Inside)

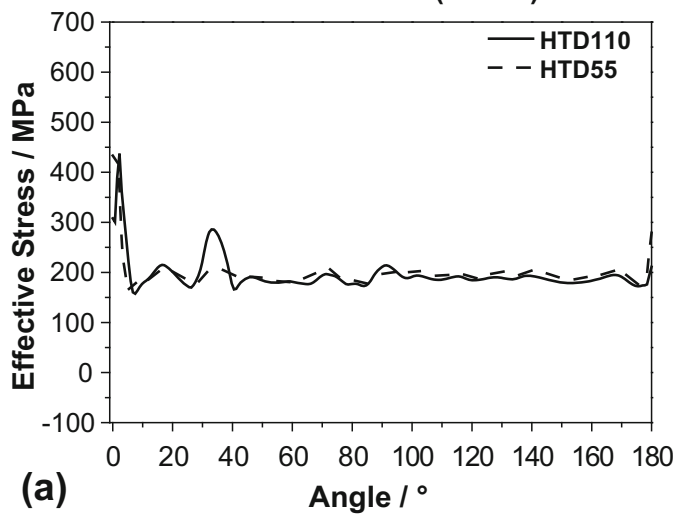

LTD110 and LTD55 (Inside)

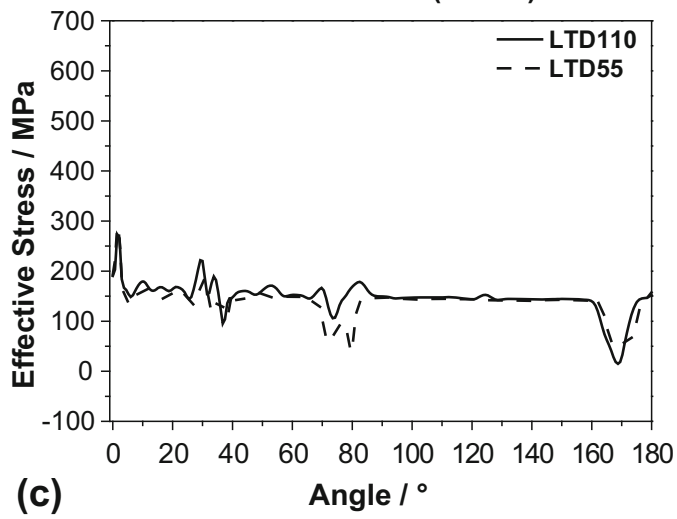

HTD110 and HTD55 (Outside)

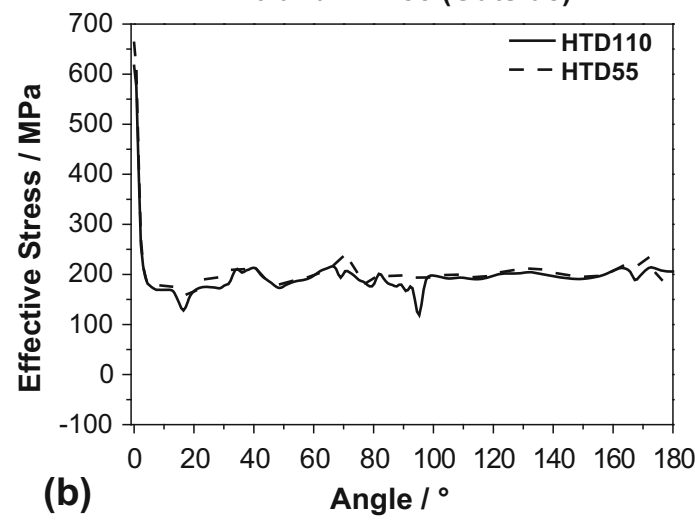

LTD110 and LTD55 (Outside)

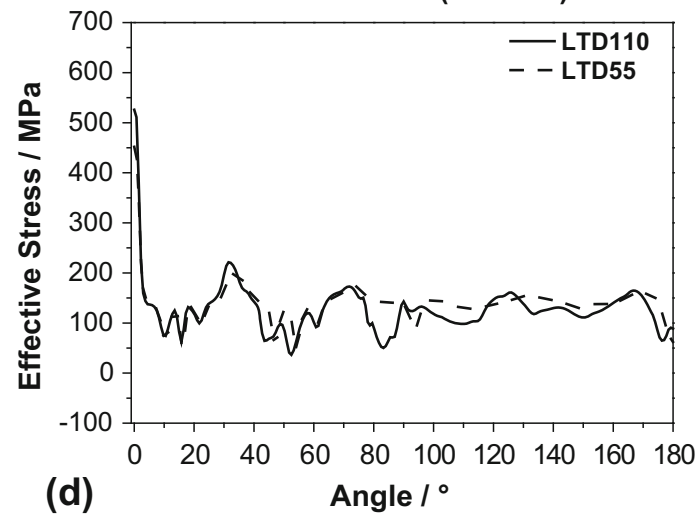

Fig. 13-FEA simulation for the pipe forming: comparison of effective stresses at $(a)$ inside and (b) outside of J55 and P110 pipes with high T/ $\mathrm{D},(c)$ inside and $(d)$ outside of J55 and P110 pipes with low T/D. Angle means the angular distance from the welding zone (0 deg) in the circumferential direction.

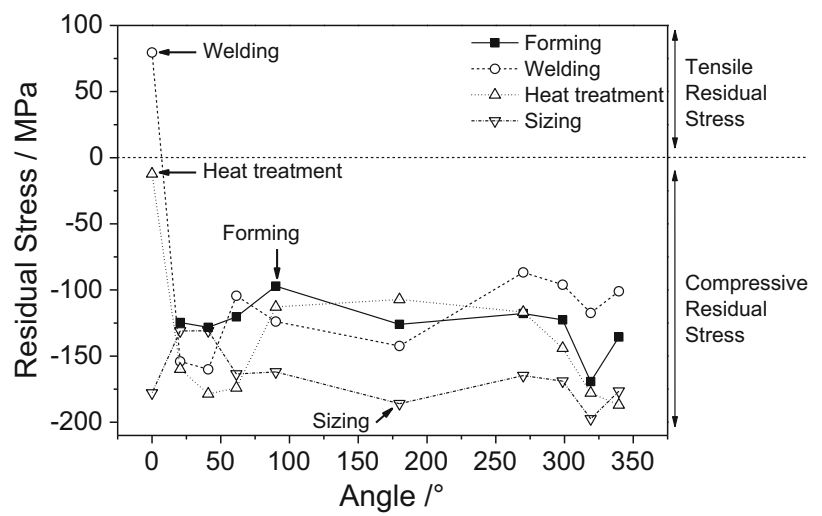

Fig. 14-Residual stresses measured in each ERW step. After the welding tensile residual stress was observed in the welding zone ( $0 \mathrm{deg})$. Note that the residual stress cannot be measured in $0 \mathrm{deg}$ after forming since the edges of pipe are not connected yet.

that the lower bainitic or martensitic weld metal is marginally susceptible to hydrogen embrittlement in ERW X46 linepipe steels, ${ }^{[6]}$ but hydrogen in welding region is related to the degradation of mechanical properties. ${ }^{\left[28,{ }^{29]}\right.}$ With reasonable doubts, we evaluated the diffusible hydrogen contents in the investigated steel pipes. Figure 11 shows the $\operatorname{TDS}^{[27]}$ results. The samples from pipes without crack show smaller amount of hydrogen both in base material and welding zone, compared to the samples from pipes with crack. Although absolute amounts of hydrogen contents are very small $(<1 \mathrm{ppmw})$, it shows the different order of magnitude between the cases. To confirm the differences of hydrogen contents between pipes with or without crack, TDS analyses were conducted for the two samples that the one selected from the base material without crack and the other from the welding zone with crack in $\mathrm{J} 55$ steel pipes. It was expected that hydrogen contents measured in both samples should be similar and show same order of magnitude after the second TDS experiment since the diffusible hydrogen must be diffused out during the first TDS experiment. After the second TDS, the hydrogen contents for samples from base material without crack and welding zone with crack were measured as 0.014 and $0.031 \mathrm{ppmw}$, respectively. It implies that the amount of diffusible hydrogen contents in the welding zone of ERW steel pipes would be the critical culprit for the crack initiation in the vicinity of oxide inclusions as discussed above. ${ }^{[26,27]}$ However, it still needs much more detailed studies to determine the critical limit for diffusible hydrogen contents in the ERW steel pipes.

Besides the hydrogen contents, residual stress in the welding zone is important for the defects formation. Actually, when the stress is implemented, hydrogen 


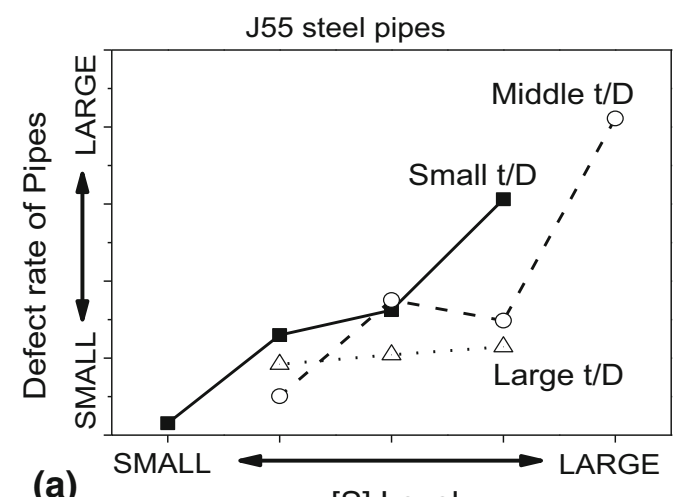

[S] Level

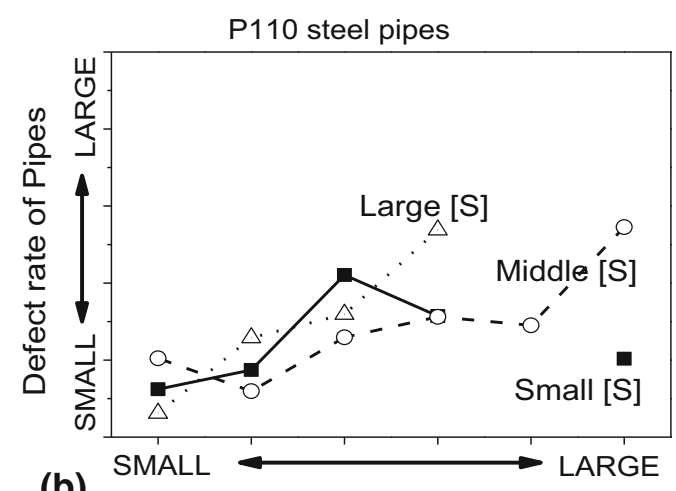

$[P]$ Level

Fig. 15-Results of the statistical analyses for big data collected from industry: $(a)$ sulfur and t/D in J55 steel pipes, $(b)$ sulfur and phosphorus in P110 steel pipes.

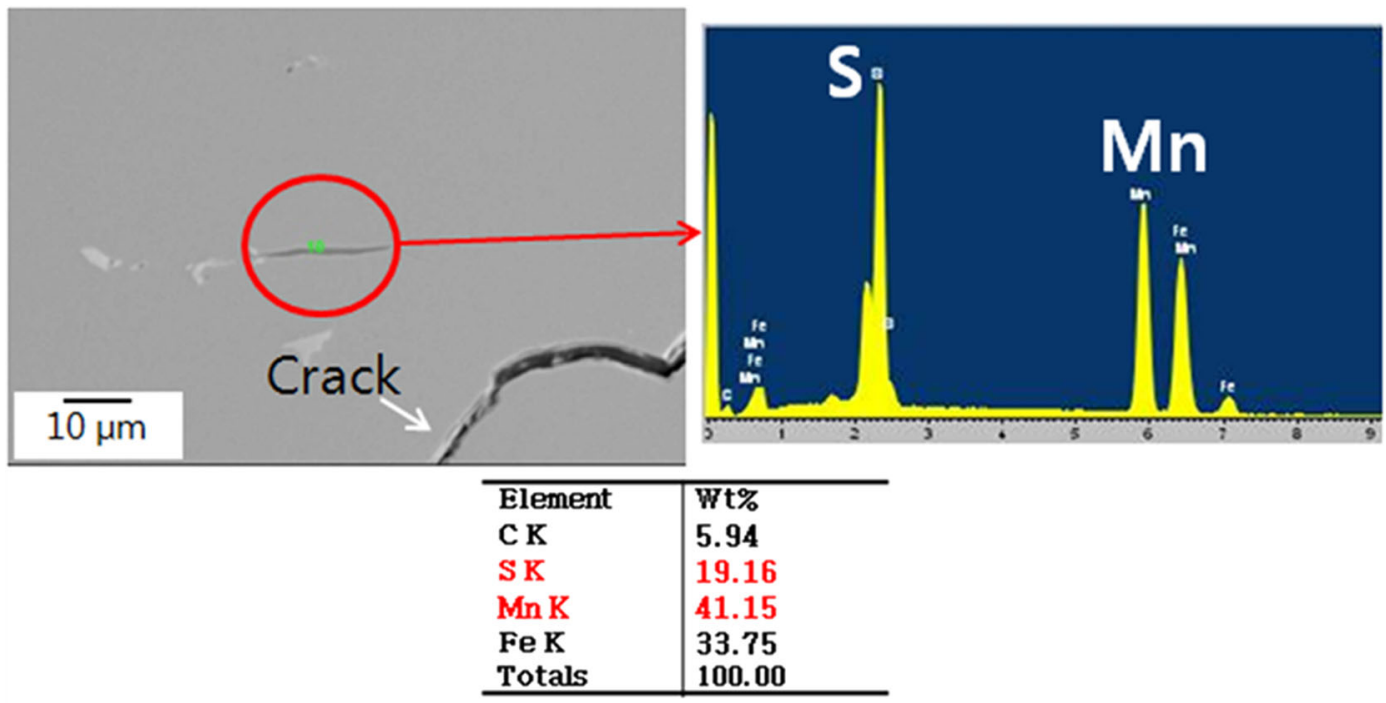

Fig. 16- MnS found near the crack tip in J55 steel pipes.

diffusivity is effectively increased, ${ }^{[30]}$ and defects will be formed easily. This means that the pipe forming and welding processes promote hydrogen embrittlement on the welding zone. In order to evaluate the effective stresses in the pipes, FEA were conducted for 4 cases as listed in Table II and the simulation results are represented in Figure 12. As expected, the higher the $\mathrm{T} / \mathrm{D}$, the higher the effective stress at all the directions in both $\mathrm{J} 55$ and P110 pipes. Especially, the effective stress in the welding zone ( 0 deg in the graph) is much higher than other positions. This is one of the reasons that the welding zone is vulnerable to the defect formation. Figure 13 shows the comparison among the steel pipes. It is worth noting that identical values of $T / D$ induce similar effective stresses although they have different mechanical properties, thickness, and ODs. This implies that the T/D is critical to the effective stress in the pipe forming.

In order to specify the critical juncture of defect formation, residual stresses were measured during ERW processes. ERW process can be divided into several steps: forming, welding, seam heat treatment, and sizing. ${ }^{[9]}$ The residual stresses were evaluated at each step in the process. Figure 14 shows the residual stresses in each step. The tensile residual stress was observed in the welding zone after welding step only. This indicates that the defect was formed just after the welding step. Note that the residual stress cannot be measured in 0 deg after forming since the edges of pipe are not connected yet.

\section{Statistical Analysis}

In the practical point of view, statistical analysis is a powerful tool to account for the real complexity of actual practices. It is helpful to determine the critical factors for the pipe integrity in terms of manufacturing. We have investigated over 250,000 pipes manufactured in industry during 6 months and collected the pipe inspection results. Data were gathered using an automatic computerized system attached to the ultrasonic inspection facility. The minimum detectable size of defect was approximately $0.1 \mathrm{~mm}$. Figure 15 shows the results of the statistical analyses for the data collected. In J55 steel pipes, sulfur is found to be the most critical 


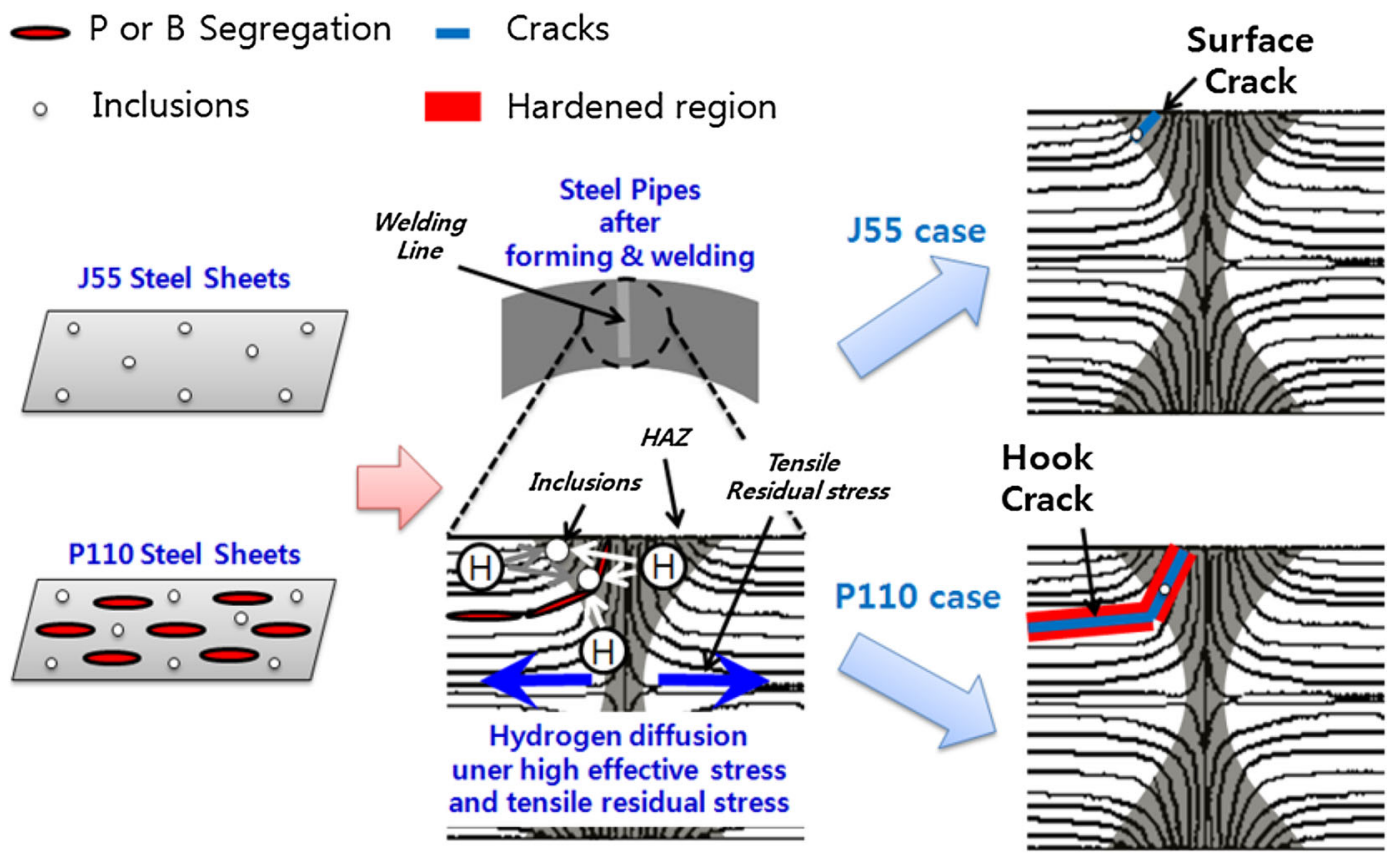

Fig. 17-Schematic diagram for the defect formations in this study.

factor for the defect rate of pipes when $\mathrm{P}$ does not show any impact (Figure 15(a)). This is interesting result since the sulfur level $(<30 \mathrm{ppm}$ in this study) is already very low for occurring defects. ${ }^{[31,32]}$ However, MnS was found near the crack tip as shown in Figure 16. Presumably $\mathrm{MnS}$ also has a role for the crack formation, and the less the sulfur, the less the sulfideassociated defect. ${ }^{[32]}$ On the other hand, phosphorous is appeared to be the most critical factor for the defect rate of P110 pipes (Figure 15(b)). As discussed above, segregation of $\mathrm{P}$ and $\mathrm{B}$ enhanced the hardenability of the steel pipes, and it helps the crack formation. It is worth noting that the $\mathrm{T} / \mathrm{D}$ shows no importance here as shown in Figure 15(a). Although the higher T/D can induce higher effective stress as discussed above, the effective stress cannot be the main culprit for the defect formation. Its role might be ancillary. Thus, in order to reduce the failure rate, level of sulfur and phosphorous should be managed as discussed.

\section{CONCLUSIONS}

Several metallurgical factors for the defect formation have been studied in two ERW API steel pipes. The work shows that two important crack types: the surface crack and hook crack, exist in the investigated steel pipes. It can be postulated that the cracks have formed after the welding step with tensile residual stress in ERW, and the inclusion, diffusible hydrogen, and effective stress are involved with the initiation of the cracks. However, the surface crack cannot propagate in a long distance since the microstructure in the vicinity of crack is identical to the base material and successfully might it retard the propagation. On the other hand, the microstructure in the vicinity of hook crack is changed to martensite after the welding due to the increased hardenability with segregations of $\mathrm{B}, \mathrm{P}$, and S. It promotes the crack propagation and results in the huge crack. Mechanisms of the crack formation can be deducted from the discussions as shown in Figure 17.

Furthermore, statistical analyses for data collected from industry have been carried out in order to provide a simple way to avoid defects in actual manufacturing. S is found to be important culprit for the J55 steel pipes when $\mathrm{P}$ is responsible for $\mathrm{P} 110$ steel pipes. Interestingly, the importance of high $\mathrm{T} / \mathrm{D}$ cannot be sustained for the defective products from the analyses. This implies that the metallurgical factors such as $\mathrm{S}, \mathrm{P}$, and $\mathrm{H}$ are important culprits for the defect formations.

\section{ACKNOWLEDGMENTS}

The authors are grateful to POSCO for support through Steel Innovation Programme, and to the National Research Foundation of Korea, Ministry of Education, Science and Technology, Project Number 10048351. The authors are grateful to Messrs S.-Y. Choi and H.-J. Kim in NEXTEEL, for their efforts in pipe inspection and sample preparation, and to Messrs H.-J. Kim, Y.-S. Cho, C.-W. Kang, and C.-H. Kim in POSCO, for their help and support in microstructural characterization. The authors would like to thank to Prof. D.-W. Suh and Ms. E. J. Song for the provision of laboratory facilities at CML, GIFT, POSTECH, and to Prof. H. S. Kim in POSTECH for help in FEA. 


\section{REFERENCES}

1. C. Boyer, B. Clark, V. Jochen, R. Lewis, and C.K. Miller: Oilfield Rev., 2011, vol. 23, pp. 28-39.

2. P. Dudenas: Petroskills, 2011, pp. 1-132.

3. C. Kato, Y. Otoguro, S. Kado, and Y. Hisamatsu: Corros. Sci., 1978, vol. 18, pp. 61-74.

4. R. Wang and S. Luo: Corros. Sci., 2013, vol. 68, pp. 119-27.

5. P.G. Fazzini and J.L. Otegui: Int. J. Press. Vessels Pip., 2007 , vol. 84, pp. 739-48.

6. M.D. Chapetti, J.L. Othgui, and J. Motylicki: Int. J. Fatigue, 2002, vol. 24, pp. 21-28.

7. M.J. Rosenfeld and J.F. Kiefner: Basics of Metal Fatigue in Natural Gas Pipeline Systems - A Primer for Gas Pipeline Operators, Pipeline Research Council International, Houston, Catalog No. L52270, 2006.

8. P. Scott: Tube Pipe, 2005, pp. 127-30.

9. T. Koide, H. Kondn, and S. Itadani: JFE Tech. Rep., 2006, vol. 7, pp. 27-32.

10. B.N. Leis and J.B. Nestleroth: Battelle's Experience with ERW and Flash Weld Seam Failures: Causes and Implications, Battelle Memorial Institute, Columbus, DTPH56-11-T$000003,2012$.

11. ISIJ Quality Management Committee: Ultrasonic Testing Methods for Welded Steel Pipe, 2008, pp. 42-54.

12. API: API Specification 5CT, 9th ed., API Publishing Services, Washington DC, 2012

13. ABAQUS, Inc.: ABAQUS User's Manuals, Version 6.6, USA, 2006.

14. W. Mizutani and K. Nakajima: Trans. Iron Steel Inst. Jpn., 1981, vol. 21, pp. 895-910.

15. J.I. Jang: J. Ceram. Process. Res., 2009, vol. 10, pp. 391-400.

16. H.K.D.H. Bhadeshia: Prog. Mater. Sci., 1985, vol. 29, pp. 32186.
17. D.P. Fairchild, N.V. Bangaru, J.Y. Koo, P.I. Harrison, and A. Ozekcin: Weld. Res. Suppl., 1991, vol. 70, pp. 321-29.

18. F. Kiefner: Failure Analysis of Pipelines, ASM Handbook, ASM, St Paul, MN, 1997.

19. I.D. Simpson, Z. Tritsiniotis, and L.G. Moore: Ironmak. Steelmak., 2003, vol. 30, pp. 158-64.

20. J. Jiang, D. Li, Y. Peng, and J. Li: J. Mater. Process. Technol., 2009, vol. 209, pp. 4850-56.

21. P.G. Fazzini, A.P. Cisilino, and J.L. Otegui: Int. J. Press. Vessels Pip., 2005, vol. 82, pp. 896-904.

22. H.K.D.H. Bhadeshia and R.W.K. Honeycombe: Steels: Microstructure and Properties, 3rd ed., Butterworth-Heinemann, London, 2006.

23. H.K.D.H. Bhadeshia: Bainite in Steels, 2nd ed., The Institute of Materials, London, 2001.

24. C.M. Liu, T. Nagoya, K. Abiko, and H. Kimura: Metall. Trans. A, 1992, vol. 23A, pp. 263-69.

25. H.K.D.H. Bhadeshia: Prog. Mater. Sci., 2012, vol. 57, pp. 268-435.

26. M.B. Whiteman and A.R. Troiano: Corrosion, 1965, vol. 21, pp. 53-56.

27. W.Y. Choo and J.Y. Lee: J. Mater. Sci., 1982, vol. 17, pp. 193038.

28. W. Godoi, N.K. Kuromoto, A.S. Guimarães, and C.M. Lepienski: Mater. Sci. Eng. A, 2003, vol. 354, pp. 251-56.

29. Y. Kitagawa, K. Ikeuchi, T. Kuroda, Y. Matsushita, K. Suenaga, T. Hidaka, and H. Takauchi: J. Mater. Sci., 2008, vol. 43, pp. 1222.

30. M.R. Louthan, G.R. Caskey, J.A. Donovan, and D.E. Rawl: Mater. Sci. Eng., 1972, vol. 10, pp. 357-68.

31. M. Shinozaki, T. Kato, H. Hashimoto, and T. Irie: Iron Steel Inst. Jpn. (ISIJ), 1982, vol. 68, pp. 1340-47.

32. M.S. Joo, D.-W. Suh, and H.K.D.H. Bhadeshia: ISIJ Int., 2013, vol. 53, pp. 1305-14. 